\title{
ANALISA KEANDALAN SISTEM DISTRIBUSI PENYULANG KAMPUS DENGAN MENGGUNAKAN PENGGABUNGAN METODE SECTION TECKNIQUE DAN RIA
}

\author{
Gusti Putu Budi Arigandi ${ }^{1}$, Rukmi Sari Hartati ${ }^{2}$, Antonius Ibi Weking ${ }^{3}$
}

\begin{abstract}
There was many reliability system research with several research method. Each method have their adventages and disadventages, such as Section Technique method and RIA method. Section Technique method have adventage in its easy calculation, while RIA method use momentary failure rate parameter in its calculation so its final result almost similar to research place. Based on calculation result with Section Technique method found that SAIFI value of Kampus feeder network is 0,085 times / customer / years and SAIDI value of Kampus feeder network is 0,107 minutes / customer / years. After add momentary failure rate parameter to the calculatio, found that SAIFI value of Kampus feeder network is increase to 0,094 times / customer / years and SAIDI value of Kampus feeder network is increase to 0,162 minutes / customer / years.
\end{abstract}

Intisari - Saat ini sudah banyak penelitian untuk menganalisis keandalan suatu sistem. Tiap metode memiliki kelebihan dan kekurangan masing-masing. Beberapa contoh diantaranya adalah metode Section Technique dan RIA. Metode Section Technique memiliki kelebihan di dalam perhitungannya yang mudah, sedangkan metode RIA menggunakan parameter momentary failure rate di dalam perhitungannya sehingga hasil akhir lebih sesuai dengan nilai di lapangan. Berdasarkan hasil perhitungan dengan metode Section Technique didapatkan nilai SAIFI penyulang sebesar 0,085 kali / pelanggan / tahun dan nilai SAIDI penyulang sebesar 0,107 menit / pelanggan / tahun. Setelah adanya penambahan parameter momentary failure rate ke dalam perhitungan sistem, didapatkan nilai SAIFI penyulang meningkat menjadi 0,094 kali / pelanggan / tahun dan nilai SAIDI penyulang meningkat menjadi 0,162 menit / pelanggan / tahun.

Kata Kunci Section Technique, RIA, Indeks Keandalan

\footnotetext{
1 Mahasiswa, Teknik Elektro dan Komputer Universitas Udayana, Kampus Bukit Jimbaran, Badung Bali. 80361, Tel. 0361703315 fax:0361703315; e-mail: g_and_hi@yahoo.co.id

${ }^{2}$ Dosen Teknik Elektro dan Komputer Universitas Udayana, Kampus Bukit Jimbaran, Badung Bali. 80361, Tel. 0361703315 fax:0361703315; e-mail: s_hartati@gmail.com

${ }^{3}$ Dosen Teknik Elektro dan Komputer Universitas Udayana, Kampus Bukit Jimbaran, Badung Bali. 80361, Tel. 0361703315 fax:0361703315; e-mail: weking@yahoo.co.id
}

\section{PENDAHULUAN}

Keandalan sistem adalah kemampuan suatu sistem untuk bekerja sesuai dengan fungsinya dalam kurung waktu tertentu. Nilai suatu keandalan sistem dapat dilihat dari berapa banyak sistem mengalami gangguan dan berapa lama waktu yang dibutuhkan untuk memperbaiki gangguan tersebut [1].

Saat ini sudah banyak penelitian keandalan sistem dengan menggunakan berbagai macam metode penelitian, seperti Reliability Indeks Assessment (RIA) dan Section Technique. Masing-masing metode memiliki keunggulan dan kekurangan. Berdasarkan penelitian sebelumnya yang dilakukan oleh Wicaksono [2], didapatkan bahwa metode Section Technique membagi struktur jaringan menjadi beberapa bagian guna mempermudah di dalam menganalisis sistem, dan tiap seksi memiliki perhitungan masing-masing. Hasil dari tiap seksi akan dijumlahkan menjadi hasil akhir dari indeks keandalan sistem. Namun di dalam perhitungannya, metode section technique ini hanya menggunakan failure rate yang umum digunakan untuk tiap komponen sistemnya, yakni sustained failure rate.

Oleh karena itu, di dalam penelitian ini akan digunakan metode lain yang menggunakan momentary failure rate di dalam perhitungannya. Berdasarkan penelitian yang dilakukan oleh Disyon [3], perhitungan momentary failure rate ini dapat diaplikasikan ke dalam perhitungan indeks keandalan dengan menggunakan metode RIA. Metode RIA ini memperhatikan laju kegagalan yang diakibatkan oleh gangguan sementara (momentary failure rate), sehingga hasil akhir dari metode ini lebih mendekati hasil sebenarnya di lapangan.

Di dalam penelitian ini akan menggabungkan metode Section Technique yang membagi wilayah penyulang menjadi beberapa bagian dengan LBS maupun Recloser sebagai pembatasnya, yang kemudian di dalam perhitungan indeks keandalannya akan dimasukkan metode RIA sehingga hasil akhir dari penelitian ini lebih mendekati hasil sebenarnya di lapangan.

Penyulang Kampus memiliki tipe jaringan radial, dengan panjang saluran $21,377 \mathrm{~km}$. Selain itu, penyulang ini memiliki trafo distribusi sebanyak 57 buah dengan total jumlah pelanggan mencapai 7099 pelanggan. Penyulang Kampus memiliki beberapa peralatan sectionalizer di dalamnya, dimana peralatan ini merupakan syarat untuk menganalisis keandalan sistem dengan metode section technique. 


\section{KOMPONEN PERHITUNGAN KEANDALAN}

\subsection{Failure Rate $(\lambda)$}

Laju kegagalan didefinisikan sebagai nilai atau jumlah dari gangguan dalam suatu interval waktu tertentu. Laju kegagalan dapat dihitung dengan persamaan berikut [4] :

$$
\lambda=\frac{\text { jumlah kegagalan }}{\text { total waktu operasi unit }}
$$

Berdasarkan penyebab terjadinya kegagalan, laju kegagalan dapat dibagi menjadi 2 jenis, yakni :

a. Sustained failure rate yang merupakan nilai laju kegagalan yang diakibatkan oleh gangguan yang memiliki interval waktu yang cukup lama di dalam periode perbaikannya. Jenis laju kegagalan ini yang umum digunakan untuk perhitungan indeks keandalan suatu sistem distribusi.

b. Momentary failure rate merupakan nilai laju kegagalan yang disebabkan oleh gangguan sesaat yang dialami oleh suatu komponen.

\subsection{Unavailability $(\mathrm{U})$}

Ketidaktersediaan adalah waktu dimana sistem tidak dapat menyuplay daya ke pelanggan. Ketidaktersediaan juga berarti durasi gangguan dan disimbolkan huruf $\mathrm{U}$ besar.

Berikut ini tabel data kegagalan untuk Saluran Udara Tegangan Menengah (SUTM) sesuai Standar PLN No. 59 Tahun 1985 mengenai "Keandalan pada Sistem Distribusi 20 $\mathrm{kV}$ dan $6 \mathrm{kV}$ " yang meliputi nilai failure rate, repair time, dan switching time [2] :

Tabel 1: Data indeks kegagalan SUTM

\begin{tabular}{|l|c|}
\hline \multicolumn{2}{|c|}{ Saluran Udara } \\
\hline Sustained failure rate $(\lambda / \mathrm{km} /$ tahun $)$ & 0,2 \\
\hline Momentary failure rate $(\lambda / \mathrm{km} /$ tahun $)$ & 0,003 \\
\hline Repair time $(\mathrm{r})(\mathrm{jam})$ & 3 \\
\hline Switching time (rs) (jam) & 0,15 \\
\hline
\end{tabular}

Nilai failure rate, repair time, dan switching time komponen yang terdapat di dalam sistem distribusi dapat dilihat pada tabel di bawah ini [2] :

Tabel 2: Data indeks kegagalan peralatan

\begin{tabular}{|l|c|c|c|}
\hline Komponen & $\lambda$ (unit/thn) & $\mathrm{r}(\mathrm{jam})$ & $\mathrm{rs}(\mathrm{jam})$ \\
\hline Trafo & 0,005 & 10 & 0,15 \\
\hline CB & 0,004 & 10 & 0,15 \\
\hline Sectionalizer & 0,003 & 10 & 0,15 \\
\hline
\end{tabular}

Parameter-parameter yang umum dihitung untuk mengetahui keandalan suatu sistem, antara lain failure rate $(\lambda)$ dan unavailability (U). Parameter yang dihitung untuk sistem distribusi adalah parameter $\lambda$ dan $U$ pada setiap titik beban (load point) pada jaringan sistem distribusi tersebut. Berikut ini merupakan perhitungan parameter untuk setiap titik beban :

1. Failure Rate titik beban $\left(\lambda_{\mathrm{LP}}\right)$ merupakan hasil penjumlahan tiap peralatan tenaga listrik seperti transformator, $\mathrm{CB}$, maupun sectionalizer yang mempengaruhi titik beban yang sedang dihitung, berikut ini adalah persamaannya :

$\lambda_{\text {sys }}=\sum_{\mathrm{i}} \lambda \mathrm{i}$.

2. Unavailability titik beban $\left(\mathrm{U}_{\mathrm{LP}}\right)$ merupakan total hasil perkalian antara failure rate $(\lambda)$ dengan repair time $(\mathrm{r})$ masing-masing peralatan yang mempengaruhi titik beban yang dihitung, berikut ini adalah persamaannya :

$$
\mathrm{U}_{\mathrm{sys}}=\sum_{\mathrm{i}} \lambda \mathrm{i} . \mathrm{ri}
$$

Dimana :

$\lambda \mathrm{i}=$ failure rate untuk peralatan $\mathrm{i}$

$\mathrm{ri}=$ repair time untuk peralatan $\mathrm{i}$

Indeks keandalan yang dicari di dalam penelitian ini adalah SAIFI dan SAIDI :

a. SAIFI (System Average Interruption Frequency Index). Merupakan ukuran jumlah rata-rata dari gangguan yang terjadi dalam satu tahun dan ditetapkan ke dalam bentuk persamaan [4] :

$$
S A I F I=\frac{\sum \lambda_{i} \cdot N_{i}}{\sum N_{i}}
$$

b. SAIDI (System Average Interruption Duration Index Merupakan waktu kegagalan rata-rata dalam satu tahun untuk tiap pelanggan dan ditetapkan ke dalam bentuk persamaan [4] :

$$
S A I D I=\frac{\sum U_{i} \cdot N_{i}}{\sum N_{i}}
$$

Dimana :

$\sum \lambda_{i} \cdot N_{i}=$ jumlah perkalian antara failure rate dengan jumlah pelanggan komponen $i$

$\sum U_{i} \cdot N_{i}=$ jumlah perkalian antara durasi kegagalan $/$ unavailability dengan jumlah pelanggan komponen $i$.

\section{Metodologi}

Penelitian ini mengambil contoh sistem distribusi pada wilayah Kuta, tepatnya di Penyulang Kampus, dimana penyulang ini merupakan salah satu penyulang tipe radial dalam area PT. PLN (Persero) Distribusi Area Bali Selatan Rayon Kuta. Penelitian dimulai pada bulan Maret hingga Mei 2015. Data yang dikumpulkan bersifat data sekunder. Data yang digunakan dalam analisis penelitian ini adalah :

a. Single line diagram Penyulang Kampus

b. Data jumlah pelanggan untuk tiap titik beban

c. Data panjang saluran penyulang

d. Parameter tiap komponen sesuai SPLN No. 59 Tahun 1985 , seperti : failure rate $(\lambda)$, repair time $(\mathrm{r})$

Alur analisis dari penelitian ini adalah sebagai berikut : 
1. Menghitung keandalan penyulang dengan metode Section Technique, yaitu : membagi struktur sistem, menghitung nilai $\lambda$ dan $U$ sistem, serta menghitung indeks keandalan Penyulang Kampus.

2. Menghitung keandalan penyulang dengan metode gabungan Section Technique dan RIA, dimana pada metode ini terdapat proses pembagian struktur jaringan sistem (seperti metode Section Technique) dan adanya penambahan parameter momentary failure rate ke dalam perhitungan (seperti metode RIA).

3. Menganalisis hasil akhir dari indeks keandalan SAIFI dan SAIDI Penyulang Kampus sebelum dan sesudah adanya parameter momentary failure rate.

\section{HASIL DAN PEMBAHASAN}

\subsection{Perhitungan Keandalan Metode Section Technique}

Langkah pertama di dalam menganalisis dengan metode ini adalah membagi struktur penyulang menjadi 3 bagian. Pembagian ini didasari atas penempatan sectionalizer di dalam jaringan penyulang. Langkah berikutnya adalah menghitung nilai $\lambda$ dan $U$ dari tiap peralatan yang termasuk ke dalam perhitungan dari tiap section. Berikut ini merupakan salah satu perhitungan penentuan nilai $\lambda$ dan $U$ tiap peralatan pada section 1 :

Tabel 3: Penentuan nilai $\lambda$ dan $U$ peralatan

\begin{tabular}{|c|c|c|c|c|c|}
\hline Alat & $\begin{array}{c}\lambda \\
\text { peralatan } \\
\text { (SPLN) }\end{array}$ & $\begin{array}{c}\text { Panjang } \\
\text { Saluran }\end{array}$ & $\begin{array}{c}\lambda \\
\text { (fault/ } \\
\text { year) }\end{array}$ & $\begin{array}{c}\text { r (hour) } \\
\text { SPLN }\end{array}$ & $\begin{array}{c}\text { U } \\
\text { (hour/ } \\
\text { year) }\end{array}$ \\
\hline S1 & 0,003 & - & 0,003 & 10 & 0,03 \\
\hline S2 & 0,003 & - & 0,003 & 10 & 0,03 \\
\hline L1 & 0,2 & 0,556 & 0,1112 & 3 & 0,3336 \\
\hline L2 & 0,2 & 0,063 & 0,0126 & 3 & 0,0378 \\
\hline L3 & 0,2 & 0,114 & 0,0228 & 3 & 0,0684 \\
\hline L4 & 0,2 & 0,108 & 0,0216 & 3 & 0,0648 \\
\hline L5 & 0,2 & 0,165 & 0,033 & 3 & 0,099 \\
\hline L6 & 0,2 & 0,481 & 0,0962 & 3 & 0,2886 \\
\hline L7 & 0,2 & 0,631 & 0,1262 & 3 & 0,3786 \\
\hline L8 & 0,2 & 0,036 & 0,0072 & 3 & 0,0216 \\
\hline L9 & 0,2 & 0,266 & 0,0532 & 3 & 0,1596 \\
\hline L10 & 0,2 & 0,041 & 0,0082 & 3 & 0,0246 \\
\hline L11 & 0,2 & 0,25 & 0,05 & 3 & 0,15 \\
\hline L12 & 0,2 & 0,362 & 0,0724 & 3 & 0,2172 \\
\hline L13 & 0,2 & 0,07 & 0,014 & 3 & 0,042 \\
\hline L14 & 0,2 & 0,113 & 0,0226 & 3 & 0,0678 \\
\hline L15 & 0,2 & 0,268 & 0,0536 & 3 & 0,1608 \\
\hline L16 & 0,2 & 0,211 & 0,0422 & 3 & 0,1266 \\
\hline L17 & 0,2 & 0,03 & 0,006 & 3 & 0,018 \\
\hline L18 & 0,2 & 0,459 & 0,0918 & 3 & 0,2754 \\
\hline L19 & 0,2 & 0,328 & 0,0656 & 3 & 0,1968 \\
\hline L20 & 0,2 & 0,15 & 0,03 & 3 & 0,09 \\
\hline & & Total & 0,9514 & & 2,9312 \\
\hline
\end{tabular}

Nilai $\lambda$ pada kolom 4 pada tabel di atas, didapatkan dari perkalian nilai $\lambda$ peralatan (SPLN) dengan panjang saluran. Nilai $U$ didapatkan dari perkalian nilai $\lambda$ dengan $r$ tiap peralatan. Berdasarkan hasil tabel di atas, didapatkan bahwa nilai $\lambda$ pada section 1 adalah 0,9514 kegagalan/tahun dan nilai $\mathrm{U}$ pada section 1 adalah 2,9312 jam/tahun. Langkah selanjutnya adalah mengalikan nilai $\lambda$ section 1 dengan pelanggan serta nilai U section 1 dengan pelanggan dari tiap titik beban. Berikut ini adalah data jumlah pelanggan pada section 1 :

Tabel 4: Data jumlah pelanggan section 1

\begin{tabular}{|c|c|c|}
\hline Titik Beban & $\begin{array}{c}\text { Trafo } \\
\text { Distribusi }\end{array}$ & Jumlah Pelanggan \\
\hline LP01 & KA0072 & 377 \\
\hline LP02 & KA1366 & 9 \\
\hline LP03 & KA2614 & 12 \\
\hline LP04 & KA1857 & 5 \\
\hline LP05 & KA0328 & 452 \\
\hline LP06 & KA1487 & 6 \\
\hline LP07 & KA1842 & 2 \\
\hline LP08 & KA0867 & 336 \\
\hline LP09 & KA1445 & 2 \\
\hline LP10 & KA0196 & 353 \\
\hline LP11 & KA0149 & 419 \\
\hline LP12 & KA0199 & 202 \\
\hline LP13 & KA0869 & 78 \\
\hline LP14 & KA0908 & 113 \\
\hline LP15 & KA1624 & 3 \\
\hline LP16 & KA1991 & 235 \\
\hline LP17 & KA2525 & 8 \\
\hline
\end{tabular}

Nilai jumlah pelanggan di atas akan dikalikan dengan nilai $\lambda$ dan $U$ pada tabel 3. Sebagai contoh diambil pada titik beban 1 , nilai $\lambda \times$ pelanggan adalah sebesar $0,9514 \times 377=358,678$ dan nilai $U$ x pelanggan adalah sebesar $2,9312 \times 377=$ 1105,063 . Proses perhitungan yang sama juga dilakukan pada titik beban yang lain. Berikut ini merupakan hasil $\lambda \mathrm{x}$ pelanggan dan $\mathrm{U}$ x pelanggan dari tiap titik beban :

Tabel 5: ( $\lambda$ x pelanggan) \& (U x pelanggan) section 1

\begin{tabular}{|l|c|c|}
\hline Titik Beban & $\lambda$ x pelanggan & U x pelanggan \\
\hline LP01 & 358.6778 & 1105.0624 \\
\hline LP02 & 8.5626 & 26.3808 \\
\hline LP03 & 11.4168 & 35.1744 \\
\hline LP04 & 4.757 & 14.656 \\
\hline LP05 & 430.0328 & 1324.9024 \\
\hline LP06 & 5.7084 & 17.5872 \\
\hline LP07 & 1.9028 & 5.8624 \\
\hline LP08 & 319.6704 & 984.8832 \\
\hline LP09 & 1.9028 & 5.8624 \\
\hline LP10 & 335.8442 & 1034.7136 \\
\hline LP11 & 398.6366 & 1228.1728 \\
\hline LP12 & 192.1828 & 592.1024 \\
\hline LP13 & 74.2092 & 228.6336 \\
\hline LP14 & 107.5082 & 331.2256 \\
\hline LP15 & 2.8542 & 8.7936 \\
\hline LP16 & 223.579 & 688.832 \\
\hline LP17 & 7.6112 & 23.4496 \\
\hline TOTAL & 2485.0568 & 7656.2944 \\
\hline
\end{tabular}

Nilai dari masing-masing titik beban kemudian dijumlahkan dan didapatkan nilai $\sum \lambda_{i} . N_{i}$ dan nilai $\sum U_{i} . N_{i}$ untuk digunakan mencari indeks keandalan penyulang dengan metode Section Technique. Proses yang sama juga dilakukan 
untuk section yang lain. Berikut ini merupakan hasil perhitungan indeks keandalan :

Tabel 6: Perhitungan Indeks Keandalan Section Tech.

\begin{tabular}{|c|c|c|c|}
\hline \multirow{2}{*}{ Section } & \multicolumn{2}{|c|}{ Perhitungan Indeks Keandalan } & \multirow{2}{*}{$\begin{array}{c}\text { Jumlah } \\
\text { Pelanggan }\end{array}$} \\
\hline & $\lambda \mathrm{x}$ pelanggan & U x pelanggan & \\
\hline 1 & 2485,0568 & 7656,2944 & 2612 \\
\hline 2 & 6457,9464 & 19639,9232 & 2924 \\
\hline 3 & 1349,8068 & 4191,6534 & 1563 \\
\hline Total & 10292,81 & 31487,871 & 7099 \\
\hline
\end{tabular}

\section{a. Perhitungan SAIFI Section Technique :}

$S A I F I=\frac{\sum \lambda_{i} \cdot N_{i}}{\sum N_{i}}$

$=\frac{(\lambda x N)_{\text {section } 1}+(\lambda \times N)_{\text {section } 2}+(\lambda \times N)_{\text {section } 3}}{N_{\text {section } 1}+N_{\text {section } 2}+N_{\text {section } 3}}$

$$
=\frac{2485,06+6457,95+1349,81 \mathrm{kali} / \text { ta? } \mathrm{wn}}{2612+2924+1563 \text { pelanggan }}
$$

$=\frac{10292,81 \mathrm{kali} / \text { tahun }}{7099 \text { pelanggan }}=1,450 \mathrm{kali} /$ pelanggan $/$ tahun

\section{b. Perhitungan SAIDI Section Technique :}

$$
\begin{aligned}
& \text { SAIDI }=\frac{\sum U_{i} \cdot N_{i}}{\sum N_{i}} \\
& =\frac{(U \times N)_{\text {section } 1}+(U \times N)_{\text {section } 2}+(U \times N)_{\text {section } 3}}{N_{\text {section } 1}+N_{\text {section } 2}+N_{\text {section } 3}} \\
& =\frac{7656,3+19639,92+4191,65 \mathrm{jam} / \mathrm{ta} \text { ? } \mathrm{un}}{2612+2924+1563 \mathrm{pelanggan}} \\
& =\frac{31487,871 \mathrm{jam} / \mathrm{tahun}}{7099 \text { pelangan }}=4,436 \mathrm{jam} / \mathrm{pelanggan} / \text { tahun }
\end{aligned}
$$

\subsection{Perhitungan Keandalan Metode Gabungan}

Proses perhitungan dengan metode gabungan adalah mirip dengan metode Section Technique. Namun bedanya adalah pada saat penentuan nilai $\lambda$ dan $U$ peralatan. Pada metode section technique, nilai $\lambda$ yang digunakan hanya sustained failure rate yakni sebesar 0,2 untuk nilai Line atau salurannya. Sedangkan untuk metode gabungan ini akan menambahkan parameter momentary failure rate ke dalam perhitunganya dimana parameter ini digunakan pada metode Reliability Index Assessment (RIA), sesuai SPLN No. 59 Tahun 1985 nilai parameter ini adalah sebesar 0,003 untuk SUTM. Berikut ini adalah proses penentuan nilai $\lambda$ dan $U$ peralatan untuk section 1 dengan metode gabungan.

Tabel 7: Nilai $\lambda$ dan U peralatan metode gabungan

\begin{tabular}{|c|c|c|c|c|c|}
\hline Alat & $\begin{array}{c}\text { Sustained } \lambda \\
\text { (SPLN) }\end{array}$ & $\begin{array}{c}\text { Momentary } \lambda \\
\text { (SPLN) }\end{array}$ & $\begin{array}{c}\text { Saluran } \\
\text { (meter) }\end{array}$ & $\begin{array}{c}\lambda \\
\text { (fault/ } \\
\text { year) }\end{array}$ & $\begin{array}{c}\text { U } \\
\text { (hour/ } \\
\text { year) }\end{array}$ \\
\hline S1 & 0,003 & - & - & 0,003 & 0,03 \\
\hline S2 & 0,003 & - & - & 0,003 & 0,03 \\
\hline L1 & 0,2 & 0.003 & 0.556 & 0.113 & 0.339 \\
\hline L2 & 0,2 & 0.003 & 0.063 & 0.013 & 0.038 \\
\hline L3 & 0,2 & 0.003 & 0.114 & 0.023 & 0.069 \\
\hline
\end{tabular}

\begin{tabular}{|c|c|c|c|c|c|}
\hline L4 & 0,2 & 0.003 & 0.108 & 0.022 & 0.066 \\
\hline L5 & 0,2 & 0.003 & 0.165 & 0.034 & 0.100 \\
\hline L6 & 0,2 & 0.003 & 0.481 & 0.098 & 0.293 \\
\hline L7 & 0,2 & 0.003 & 0.631 & 0.128 & 0.384 \\
\hline L8 & 0,2 & 0.003 & 0.036 & 0.007 & 0.022 \\
\hline L9 & 0,2 & 0.003 & 0.266 & 0.054 & 0.162 \\
\hline L10 & 0,2 & 0.003 & 0.041 & 0.008 & 0.025 \\
\hline L11 & 0,2 & 0.003 & 0.25 & 0.051 & 0.152 \\
\hline L12 & 0,2 & 0.003 & 0.362 & 0.074 & 0.220 \\
\hline L13 & 0,2 & 0.003 & 0.07 & 0.014 & 0.043 \\
\hline L14 & 0,2 & 0.003 & 0.113 & 0.023 & 0.069 \\
\hline L15 & 0,2 & 0.003 & 0.268 & 0.054 & 0.163 \\
\hline L16 & 0,2 & 0.003 & 0.211 & 0.043 & 0.128 \\
\hline L17 & 0,2 & 0.003 & 0.03 & 0.006 & 0.018 \\
\hline L18 & 0,2 & 0.003 & 0.459 & 0.093 & 0.280 \\
\hline L19 & 0,2 & 0.003 & 0.328 & 0.067 & 0.200 \\
\hline L20 & 0,2 & 0.003 & 0.15 & 0.031 & 0.091 \\
\hline & & Total & 0,9605 & Total & 2,924 \\
\hline
\end{tabular}

Berdasarkan hasil tabel di atas, didapatkan bahwa nilai $\lambda$ pada section 1 adalah 0,9605 kegagalan/tahun dan nilai $U$ pada section 1 adalah 2,924 jam/tahun. Sama dengan metode sebelumnya, langkah selanjutnya adalah mengalikan nilai $\lambda$ section 1 dengan pelanggan serta nilai $U$ section 1 dengan pelanggan dari tiap titik beban :

Tabel 8: Hasil $\lambda$ x pelanggan \& U x pelanggan

\begin{tabular}{|l|c|c|}
\hline Titik Beban & $\lambda \times$ pelanggan & U p pelanggan \\
\hline LP01 & 362.111 & 1102.166 \\
\hline LP02 & 8.645 & 26.312 \\
\hline LP03 & 11.526 & 35.082 \\
\hline LP04 & 4.803 & 14.618 \\
\hline LP05 & 434.149 & 1321.430 \\
\hline LP06 & 5.763 & 17.541 \\
\hline LP07 & 1.921 & 5.847 \\
\hline LP08 & 322.730 & 982.302 \\
\hline LP09 & 1.921 & 5.847 \\
\hline LP10 & 339.059 & 1032.002 \\
\hline LP11 & 402.452 & 1224.954 \\
\hline LP12 & 194.022 & 590.551 \\
\hline LP13 & 74.919 & 228.034 \\
\hline LP14 & 108.537 & 330.358 \\
\hline LP15 & 2.882 & 8.771 \\
\hline LP16 & 225.719 & 687.027 \\
\hline LP17 & 7.684 & 23.388 \\
\hline TOTAL & 2508.842 & 7636.229 \\
\hline
\end{tabular}

Nilai dari masing-masing titik beban kemudian dijumlahkan dan didapatkan nilai $\sum \lambda_{i} . N_{i}$ dan nilai $\sum U_{i} . N_{i}$ untuk digunakan mencari indeks keandalan penyulang dengan metode gabungan section technique dan RIA. Proses yang sama juga dilakukan untuk section yang lain. Berikut ini merupakan hasil perhitungan indeks keandalan :

Tabel 9: Perhitungan Indeks Keandalan

\begin{tabular}{|c|c|c|c|}
\hline \multirow{2}{*}{ Section } & \multicolumn{2}{|c|}{ Perhitungan Indeks Keandalan } & $\begin{array}{c}\text { Jumlah } \\
\text { Pelanggan }\end{array}$ \\
\cline { 2 - 3 } & $\lambda$ x pelanggan & U x pelanggan & 2612 \\
\hline 1 & 2508.842 & 7636.229 & 2924 \\
\hline 2 & 6539.625 & 19782.620 & 1563 \\
\hline 3 & 1369.749 & 4251.480 & 7099 \\
\hline Total & 10418.216 & 31670.330 & \\
\hline
\end{tabular}




\section{a. Perhitungan SAIFI Metode Gabungan :}

$$
\begin{aligned}
& \text { SAIFI }=\frac{\sum \lambda_{i} \cdot N_{i}}{\sum N_{i}} \\
& =\frac{(\lambda x N)_{\text {section } 1}+(\lambda x N)_{\text {section } 2}+(\lambda x N)_{\text {section } 3}}{N_{\text {section } 1}+N_{\text {section } 2}+N_{\text {section } 3}} \\
& =\frac{2508,84+6539,63+1369,75 \mathrm{kali} / \text { ta? } \mathrm{un}}{2612+2924+1563 \text { pelanggan }} \\
& =\frac{10418,216 \mathrm{kali} / \text { tahun }}{7099 \text { pelangan }}=1,468 \mathrm{kali} / \text { pelanggan } / \text { tahun }
\end{aligned}
$$

\section{b. Perhitungan SAIDI Metode Gabungan :}

$$
\begin{aligned}
& \text { SAIDI }=\frac{\sum U_{i} \cdot N_{i}}{\sum N_{i}} \\
& =\frac{(U x N)_{\text {section } 1}+(U x N)_{\text {section } 2}+(U x N)_{\text {section } 3}}{N_{\text {section } 1}+N_{\text {section } 2}+N_{\text {section } 3}} \\
& =\frac{7636,229+19782,62+4251,48 \mathrm{jam} / \mathrm{ta} \text { ? } \mathrm{un}}{2612+2924+1563 \mathrm{pelang} \mathrm{gan}} \\
& =\frac{31670,33 \mathrm{jam} / \text { tahun }}{7099 \text { pelanggan }}=4,461 \mathrm{jam} / \text { pelanggan } / \text { tahun }
\end{aligned}
$$

\subsection{Analisis Keandalan Penyulang Kampus}

Berdasarkan hasil perhitungan keandalan Penyulang Kampus dengan metode Section Technique, didapatkan bahwa nilai SAIFI sebesar 1,450 kali/pelanggan/tahun (dalam 8 bulan terjadi 1 kali gangguan). Setelah adanya penambahan parameter momentary failure rate ke dalam proses perhitungan yang sama (dengan metode gabungan Section Technique - RIA), didapatkan adanya peningkatan nilai SAIFI sebesar 0,018 point yang dari awalnya 1,450 menjadi 1,468 kali / pelanggan / tahun (dalam 8 bulan 2 minggu terjadi 1 kali gangguan.

Nilai SAIDI yang didapatkan dari metode Section Technique sebesar 4,436 jam/pelanggan/tahun, namun setelah adanya penambahan parameter momentary failure rate didapatkan bahwa nilai SAIDI menjadi 4,461 jam / pelanggan / tahun atau meningkat 0,025 point dari nilai sebelumnya. Dengan kata lain, adanya parameter tambahan ini membawa pengaruh yang cukup signifikan terhadap nilai keandalan suatu sistem. Peningkatan nilai ini tentunya akan semakin besar apabila konfigurasi jaringan sistem yang diteliti memiliki panjang saluran yang lebih panjang dibandingkan Penyulang Kampus.

\section{KESIMPULAN}

Berdasarkan hasil perhitungan pada bagian sebelumnya pada Tugas Akhir ini dapat ditarik beberapa simpulan sebagai berikut :
1. Nilai SAIFI untuk Penyulang adalah sebesar 0,085 kali/pelanggan/tahun dan nilai SAIDI Penyulang adalah sebesar 0,107 jam/ pelanggan/tahun untuk metode Section Technique. Sedangkan, untuk metode gabungan Section RIA, didapatkan bahwa nilai SAIFI sebesar 0,094 kali/pelanggan /tahun dan nilai SAIDI sebesar 0,162 jam/pelanggan/tahun.

2. Adanya parameter momentary failure rate ke dalam perhitungan keandalan berdampak signifikan pada hasil akhir dari indeks keandalan sistem. Berdasarkan hasil perhitungan, didapatkan adanya peningkatan nilai hasil indeks keandalan, baik SAIFI maupun SAIDI. Nilai SAIFI meningkat 0,018 point, sedangkan nilai SAIDI meningkat sebesar 0,025 point

3. Berdasarkan hasil akhir dari tiap metode yang digunakan, dapat diketahui bahwa nilai keandalan Penyulang Kampus masih memenuhi standar PLN untuk mencapai World Class Service (WCS), yaitu nilai SAIFI sebesar 3 kali / pelanggan / tahun dan nilai SAIDI sebesar 100 menit / pelanggan / tahun (1,67 jam / pelanggan / tahun).

\section{REFERENSI}

[1] Chowdhury, A. dan Koval, D. 2009. Power Distribution System Reliability Practical Methods and Applications. New Jersey : IEEE Press.

[2] Wicaksono, H.P., Hernanda, S., dan Penangsang, O. 2012. Analisis Keandalan Sistem Distribusi di PT. PLN (Persero) APJ Kudus Menggunakan Software ETAP dan Metode Section Technique. Jurnal Teknik ITS Vol. 1, No. 1 ISSN : 2301-9271.

[3] Disyon. 2008. "Analisa Keandalan Sistem Distribusi dengan Metode RIA (Reliability Index Assessment) Studi Kasus Sistem Distribusi Jawa Timur Penyulang GI Waru" (tugas akhir). Surabaya : Universitas Kristen Petra.

[4] Brown, R. 2009. Electric Power Distribution Reliability. Second Edition. New York : CRC Press Tylor \& Francis Group.

[5] PLN (Persero), PT. 1985. SPLN No. 59 : Keandalan pada Sistem Distribusi $20 \mathrm{kV}$ dan $6 \mathrm{kV}$. Jakarta : Departemen Pertambangan dan Energi Perusahaan Umun Listrik Negara.

[6] Billinton, R. dan Allan, R. 1996. Reliability Evaluation of Power Systems. Second Edition. New York : Plenum Press.

[7] Partawan, Nyoman. 2014. "Studi Perbandingan Keandalan Sistem Distribusi $20 \mathrm{kV}$ Menggunakan Metode Section Technique dan RNEA pada Penyulang Renon" (tugas akhir). E-Journal SPEKTRUM Vol. 1, No. 1. Denpasar: Universitas Udayana.

[8] Sukerayasa, I Wayan dan Musthopa. 2008. Evaluasi Keandalan Penyulang dengan Metode Reliability Network Equivalent Approach Majalah Ilmiah Teknologi Elektro Vol. 7, No. 1. Bali : Universitas Udayana.

[9] Suhadi, dkk. 2008. Teknik Distribusi Tenaga Listrik Jilid 1. Jakarta Departemen Pendidikan Nasional.

[10] Doloksaribu, P. 2010. Analisa Keandalan Sistem Distribusi Tenaga Listrik. Jurnal Teknik Elektro Univ. Cendrawasih Vol. 1, No. 1 ISSN : 2086-9487. 